\title{
Multimedia Educational Material and Remote Laboratory for Sliding Mode Control Measurements
}

\author{
Bela Takarics ${ }^{\dagger}$, Gabor Sziebig*, Bjørn Solvang**, and Peter Korondi* \\ $\dagger *$ Dept. of Mechatronics, Optics and Eng. Info., Budapest Univ. of Technology and Economics, Budapest, Hungary \\ ** Dept. of Industrial Engineering, Narvik University College, Narvik, Norway
}

\begin{abstract}
The paper presents a multimedia educational program of DC servo drives for distant learning with a special emphasis on sliding mode control. The program contains of three parts: animation, simulation and internet based measurement. The animation program explains the operation of DC motors, gives its time- and frequency-domain equations, transfer functions and the theoretical background necessary for controller design for DC servo motors. The simulation model of the DC servo motor and the controller can be designed by the students based on the animation program. The students can also test their controllers through the internet based measurement, which is the most important part from engineering point of view. After the measurements are executed, the students can download the measured data and compare them to the simulation results.
\end{abstract}

Key Words: Distance measurements, e-learning, Electrical engineering education, Sliding mode control

\section{INTRODUCTION}

The e-learning material described in this paper is presented in B.Sc. and M.Sc. courses for education of integrated and mechatronics engineers. The students learn about the basics of electric motors, control and software engineering, power electronics first and later about motion control which integrates their previous study. Explaining the sophisticated processes of servo systems and their control methods is a real challenge by the traditional methods. The static figures shown by books or the computer projector with PowerPoint are not well suited for individual distant learning. On the other hand the possibilities by the modern multimedia methods can optimally be adapted in this area. Utilizing the opportunities of the technique, the sequence of topologies and transient processes of the system can well be shown by animated figures and understood easier. Within the framework of the Leonardo da Vinci program of the European Union (EU), a project called INETELE incorporating eight Universities from eight member countries is aimed at developing multimedia software for teaching the subject of Electrical Engineering (EE) [1], [2]. The present paper is concerned only with a small fraction of the program developed by the team at the Budapest University of Technology and Economics with emphasis on sliding mode control.

So far the E-learning and Distance-learning via the Internet, is focusing on information delivery where typically multimedia

\footnotetext{
Manuscript received May 3, 2010; revised Sep. 15, 2010

† Corresponding Author: takarics@mogi.bme.hu

Tel: +36 1463-2602, Fax: +36 1463-3787, Budapest Univ. of Technology and Economics

* Dept. of Mechatronics, Optics and Eng. Info., Budapest Univ. of Technology and Economics, Hungary

** Dept. of Industrial Engineering, Narvik University College, Norway
}

rich web pages are offered to the student sitting at home in front of the computer, taking lessons in a certain subject, while keeping contact to other students and teacher via e- mail, chatrooms, on-line tests, etc [3]. Other issues focus on the style of teaching under the impression of extensive usage of multimedia like video-clips, audio or "slide shows" in the classroom or via distance (internet). Advanced material use interactivity and combination of text explaining the theory with interactive programs that allow student to do little experiments via a simulator or solving some engineering problems [4].

However it is crucial to let students have some real practice. The real experiment gives the students a sense of practical testing and they can also see the influence of the second/higher order effect, real time effects, effect of parasitic which is difficult or impossible to be simulated perfectly. The reason is that the simulation is always based on more or less simplified model. To build an experiment is expensive and it is impossible for an educational institute to have the complete scale of experiments. The hardware experiment should therefore be redesigned in such way that they also can be accessed through the internet. This way the advance in Information and Communication Technologies (ICT) will be combined with real practical experience. The proposed virtual or distance laboratory does not represent any web-based simulation. It is a real electro-technical experiment conducted in the laboratory but remotely accessed, controlled and monitored by web-based tools. The experiment is either conducted online or based on recorded valued (virtual experiment). It allows students to perform experiment safely and without guidance. Official working hours in the laboratory are not limiting the users. A description about the remote laboratory is given in [5]. 


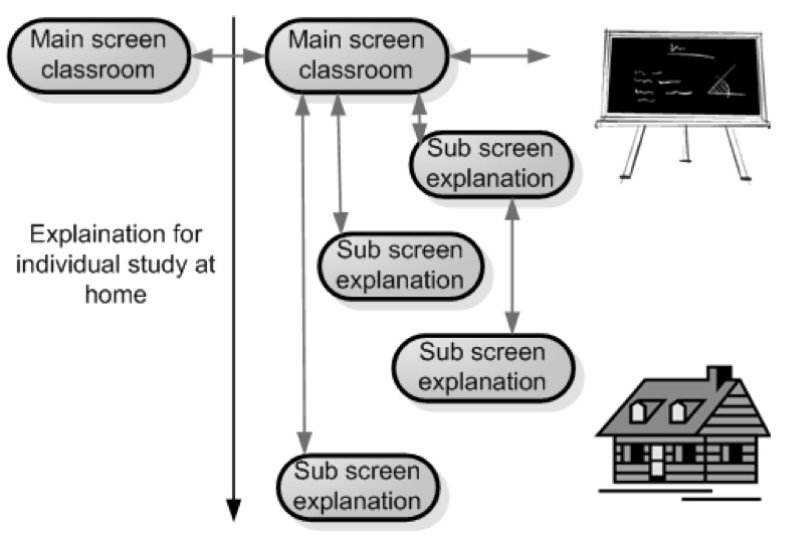

Fig. 1. Structure of the screens.

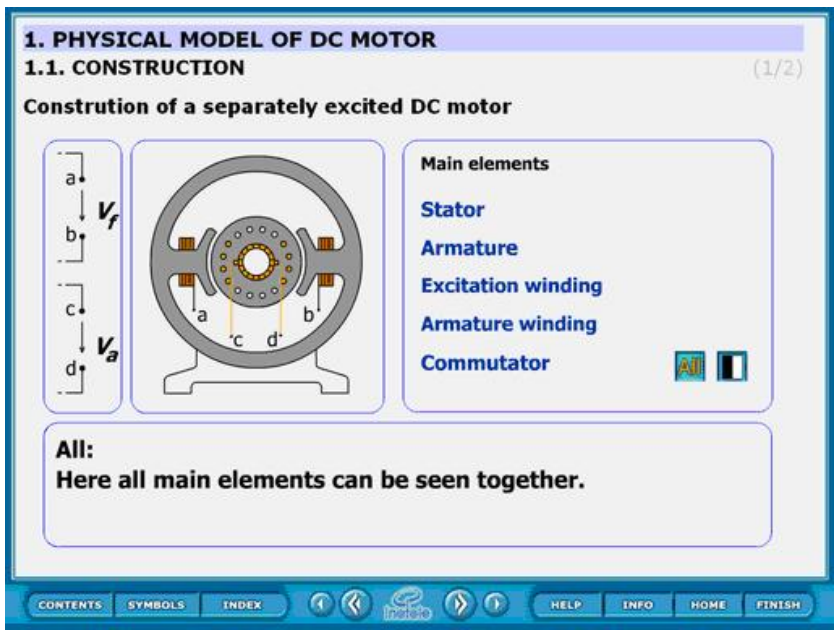

Fig. 2. Construction of a DC motor.

DC motors have played a special historical role in the field of industrial electronics since all industrial servo drives used DC motors in the past and the first microprocessor controlled drive [6] also applied DC motor. Even if they have several drawbacks they are used in recent applications [7]-[9]. The main advantage of a DC servo motor drive is that it is simple from the point of view of control. Before the advent of micro controllers they were the only solutions for servo drive systems. It is easy to adopt any control method for a DC servo system. That is why the newly proposed control methods are frequently applied for a DC servo system first. On the other hand, there is a trend to control all kind of servo drives (field oriented induction motor drives [10] and brushless drives [11]) like a DC servo drive. A description of the general animation slides for the DC motor is given in [12].

PID controller is still the most common controller method in the industrial applications. A more advanced, popular method is the sliding mode control, which was introduced in the late 1970's [13] but it is used recently in high-performance motion control systems [14]. In recent applications, the sliding mode control is combined with different soft computing methods [15], [16]. Sliding mode control of variable structure systems has a special role in the field of robust control. On one hand, the exact description of sliding mode needs advanced

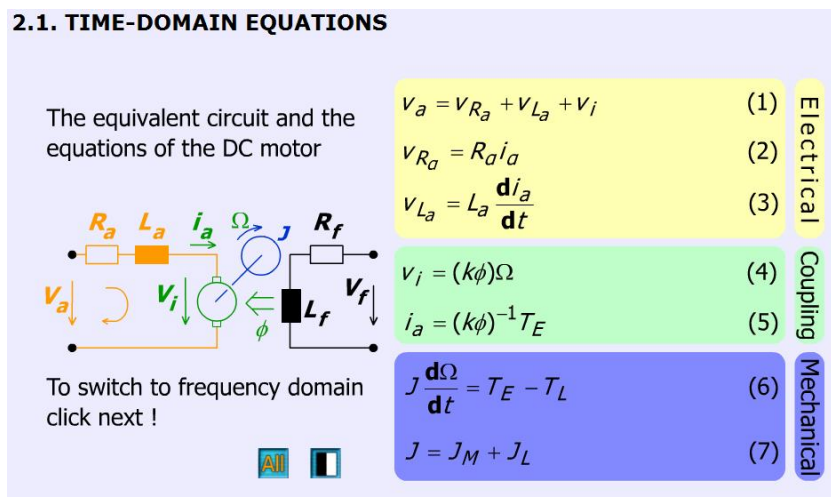

Fig. 3. Time-domain equations.

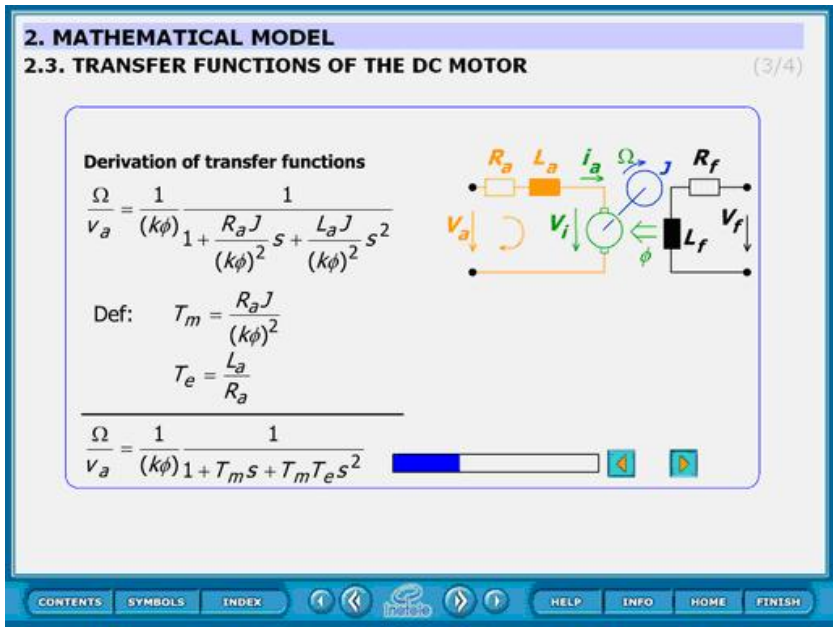

Fig. 4. Derivation of the transfer function of a DC motor.

mathematics, which was established by [17], [18] in the early sixteen's. On the other hand, it is quite easy to implement in most engineering systems, a simple relay is necessary in most cases.

The paper gives an overview of the multimedia educational program for sliding mode control of a DC servo drive with web-based laboratory measurements results with a special emphasis on sliding mode control. The organization of the paper is as follows: Section II gives the basic theory of Sliding Mode Control, Section III describes the concept of the animation and presents some selected parts of the animation program. Section IV summaries simulations. Section V presents the internet based laboratory measurements with Sliding Mode Control. Section V concludes the paper.

\section{Basic Theory of Sliding Mode Control}

The design of a sliding-mode controller consists of three main steps. First is the design of the sliding surface, the second step is the design the control law which holds the system trajectory on the sliding surface, and the third and key step is the chattering-free implementation.

\section{A. Sliding surface design}

The following linear time invariant (LTI) system is considered; first the reference signal is supposed to be constant and 


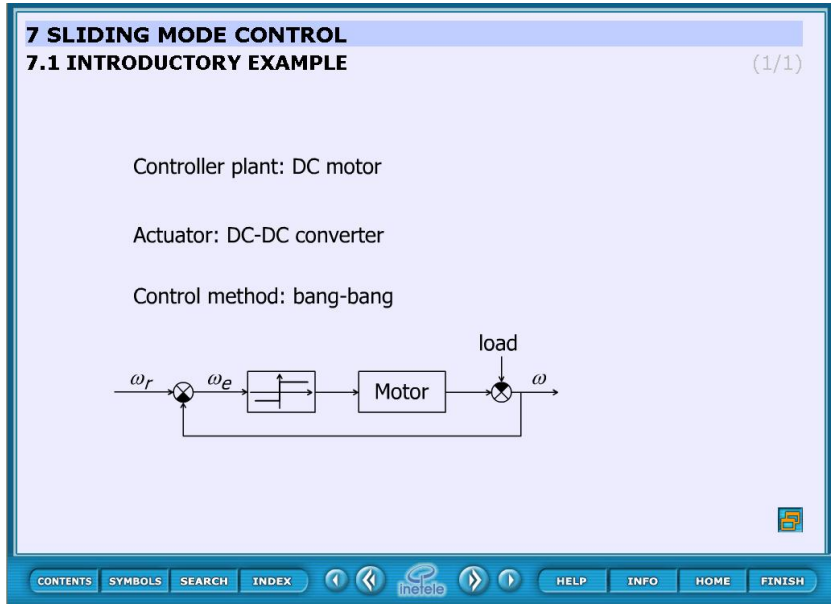

Fig. 5. Sliding mode control - a simplified system.

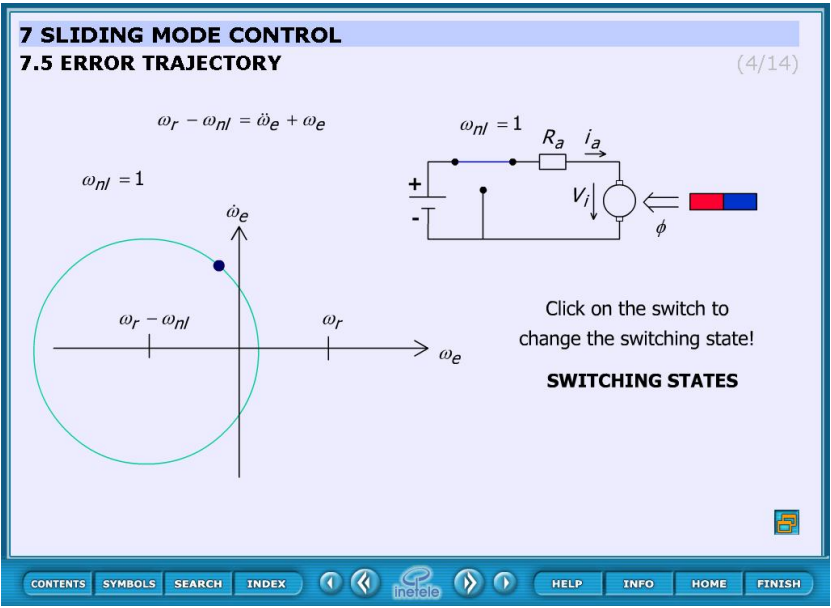

Fig. 6. Error trajectory when the DC motor is switched on.

zero. A single input multi output system is discussed. The system is transformed to a regular form [19].

$$
\begin{aligned}
& \left(\begin{array}{c}
\dot{x}_{1} \\
\dot{x}_{2}
\end{array}\right)=\left(\begin{array}{ll}
\mathbf{A}_{11} & \mathbf{A}_{12} \\
\mathbf{A}_{21} & \mathbf{A}_{\mathbf{2 2}}
\end{array}\right)\left(\begin{array}{l}
x_{1} \\
x_{2}
\end{array}\right)+\left(\begin{array}{c}
0 \\
\mathbf{B}_{2}
\end{array}\right) u \begin{array}{l}
x_{1} \in R^{n-1} \\
x_{2} \in R \\
\\
y=\mathbf{C}\left(\begin{array}{l}
x_{1} \\
x_{2}
\end{array}\right)+\mathbf{D} u \\
y \in R
\end{array}
\end{aligned}
$$

with input $u$, output $y$, state vector $x$ and $\mathbf{B}_{\mathbf{2}}>\mathbf{0}$.

The switching surface, $\sigma$ of the sliding mode, where the control has discontinuity, can be written in the following form, where $\mathbf{K}$ is the "surface vector".

$$
\sigma=x_{2}+\mathbf{K} x_{1}=0, \sigma \in R \text { and } \mathbf{K} \in R^{(n-1)} .
$$

When sliding mode occurs (when $\sigma=0$ and $x_{2}=-\mathbf{K} x_{1}$ ), the design problem of the sliding surface can be regarded as a linear state feedback control design for the following subsystem:

$$
\dot{x}_{1}=\mathbf{A}_{11} x_{1}+\mathbf{A}_{\mathbf{1 2}} x_{2} .
$$

In (3) $x_{2}$ can be considered as the input of the subsystem. A state feedback controller $x_{2}=-\mathbf{K} x_{1}$ for this subsystem gives the switching surface of the whole VSS controller. In

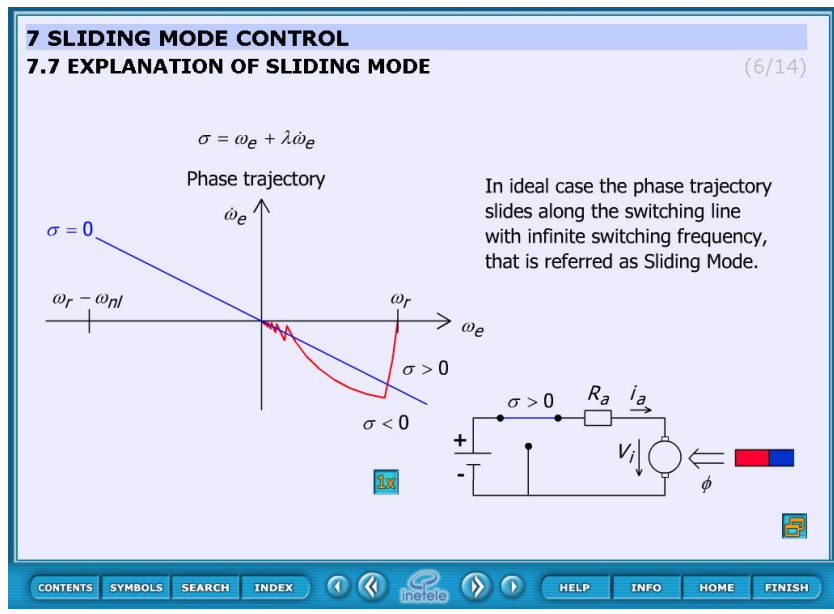

Fig. 7. Sliding mode.

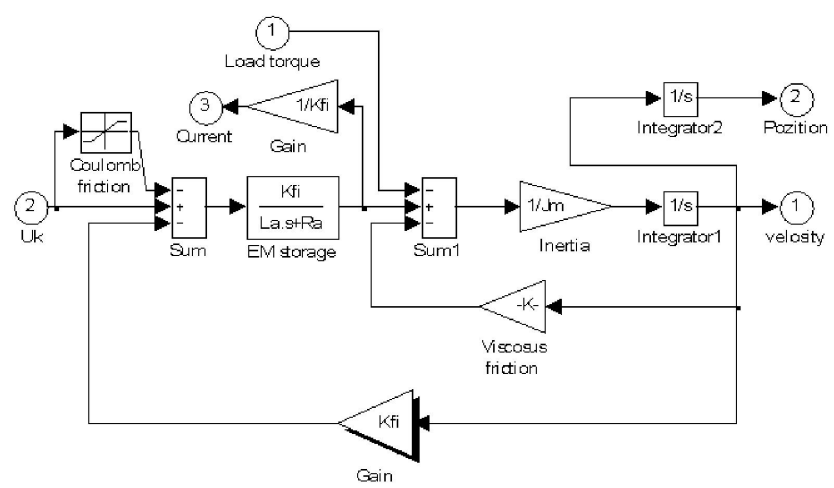

Fig. 8. Simulink model of a DC motor.

sliding mode

$$
\dot{x}_{1}=\left(\mathbf{A}_{11}-\mathbf{A}_{\mathbf{1 2}} \mathbf{K}\right) x_{1} .
$$

Various linear control design methods based on state feedback (pole placement, LQ optimal, frequency shaped method, $H \infty$ ) were proposed for (4) to design the switching surfaces in the last decade.

\section{B. Control Law}

To ensure that the system remains in the sliding mode ( $\sigma=$ 0 ) the condition

$$
\dot{\sigma} \sigma<0
$$

should hold. The simplest control law which can lead to sliding mode is the relay:

$$
u=M \cdot \operatorname{sign}(\sigma) .
$$

This is easy to realize by power electronic circuits. The relay type of controller can directly control the semiconductor switching elements, but it does not ensure the existence of sliding mode for the whole state space, and relatively big values of $M$ is necessary which might cause a severe chattering phenomenon. This control law is preferable if the controller's sample frequency is nearly equal to the maximum switching frequency of semiconductor switching elements.

If sliding mode exists then there is a continuous control, socalled "equivalent" control, $u_{e q}$, which can hold the system on the sliding manifold. It can be calculated from $\dot{\sigma}=0$ 


$$
\begin{aligned}
& \dot{\sigma}=\dot{x}_{2}+\mathbf{K} \dot{x}_{1}=0 \\
& \dot{\sigma}=\mathbf{A}_{\mathbf{2 1}} \mathbf{x}_{\mathbf{1}}+\mathbf{A}_{\mathbf{2 2}} \mathbf{x}_{\mathbf{2}}+\mathbf{B}_{\mathbf{2}} \mathbf{u}+\mathbf{K}\left(\mathbf{A}_{\mathbf{1 1}} \mathbf{x}_{\mathbf{1}}+\mathbf{A}_{\mathbf{1 2}} \mathbf{x}_{\mathbf{2}}\right)=\mathbf{0}
\end{aligned}
$$

$u_{e q}$ can be expressed from (7)

$$
u_{e q}=-\left(\left(A_{21}+K A_{11}\right) x_{1}+\left(A_{22}+K A_{12}\right) x_{2}\right) / B_{2}
$$

In the practice, there is never perfect knowledge of the whole system and its parameters. Only $\hat{u}_{e q}$, the estimation of $u_{e q}$, can be calculated. Since $u_{e q}$ does not guarantee the convergence to the switching manifold in general, a discontinuous term is usually added to $\hat{u}_{e q}$.

$$
u=\hat{u}_{e q}+M \cdot \operatorname{sign}(\sigma) .
$$

The control laws (9) do not control the semiconductor switching elements directly; additional PWM is needed. Usually, this is no problem in the case of DC servo control since the switching frequency of the semiconductor elements can be much higher than the sampling frequency of the fastest digital controller.

\section{Chattering free implementation}

The chattering in the basic sliding mode control is essentially due to the requirement that the system state must stick to the switching surface. There are several solutions for elimination of chattering, for example sector sliding mode [20].

\section{Animation OF SLIDES}

Explaining the sophisticated processes of servo systems and their control methods is a real challenge by the traditional methods. The static figures shown by books or the computer projector with PowerPoint are not well suited for individual distance learning. On the other hand the possibilities by the modern multimedia methods can optimally be adapted in this area. Utilizing the opportunities of the technique, the sequence of topologies and transient processes of the system can well be shown by animated figures and understood easier. The basics of the method in most cases is the application of simulation techniques to obtain the results representing the complex processes. The advantages of animated representation are obvious in the study of both simple and complex units.

There are basically two kinds of screens: S1; Screens for teaching in class. S2; Screens containing Supporting Text. S1 is designed for projection in classroom. Large letters, figures, tables are used. The information content is limited. S2 is designed for using it out of class-room for individual study. It applies smaller letters, figures, tables and contains substantial amount of information. It makes possible to study and learn the material of screens S1 at home for students without teacher. The Problems/Questions and Interactive Study are presented in the form of screen S2. There are two kinds of screen S1.: S1A contains animation, S1B has no animation at all. The second one is used to introduce or explain, support the screen S1A.

\section{A. Physical model of DC motor}

The first slide starts with a basic introduction of the physical model of the DC motor including its construction, which can be seen in Fig. 2. The chapter contains 2 subchapters. Both are animated.

\section{B. Time-domain equations}

This chapter focuses on the equivalent circuit of the DC motor and the time-domain equations. The animation contains 9 identical frames, which are represented by Fig. 3 .

\section{Transfer functions of a DC motor}

It explains the derivation of the transfer function of the DC motor in a detailed form step-by-step. The animation contains 13 individual (and 132 intermediate for floating equations technic) frames. This animation uses a very special way to explain the derivation. On the first page there are the initial equations. More initial equations appear than they slide into the result equations. This system repeats itself until the desired derivation ends. By clicking the two PLAY buttons the animation can go forward (right play button) or backward (left play button).

\section{Block diagram of a DC motor}

The animation contains 4 individual (and 127 intermediate) frames. In this animation the progress bar is applied as well as in the previous subchapter can be seen.

\section{E. Sliding Mode Control}

The slides discuss PID control in detail, but that is beyond the scope of this paper. We will deal with a more advanced method, the sliding mode control here.

The controlled plant is a DC motor, the actuator is a DCDC converter and the control method is bang-bang type. This means that the DC motor is controlled by a 2 state relay, which can accelerate or decelerate the motor (see in Fig. 5). The center of the error trajectory circle depends on the switching state of the DC-DC chopper as shown in the animated Fig. 6. Finally, the suppressing process of the error is shown in the animated Fig. 7.

\section{Simulation of A DC Servo Drive}

The first step from theory to application is simulation, which also has some challenges students have to solve [21]. The students use Matlab-Simulink software. The simulation model of a DC servo motor and drive is shown in Fig. 8.

The students can build a sliding mode controller in Simulink for the DC model shown in Fig. 8. Simulation model can be seen in Fig. 9 and the simulation results can be shown in Fig $10-11$. 


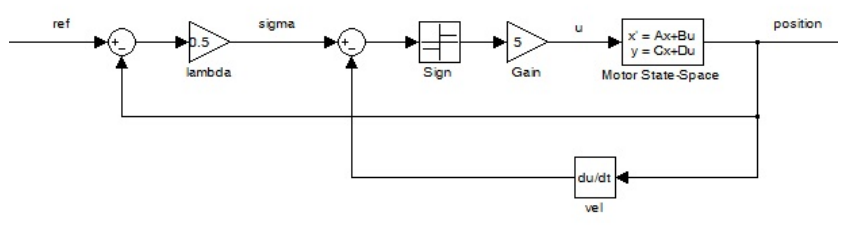

Fig. 9. Simulink model of a DC servo drive with sliding mode control.

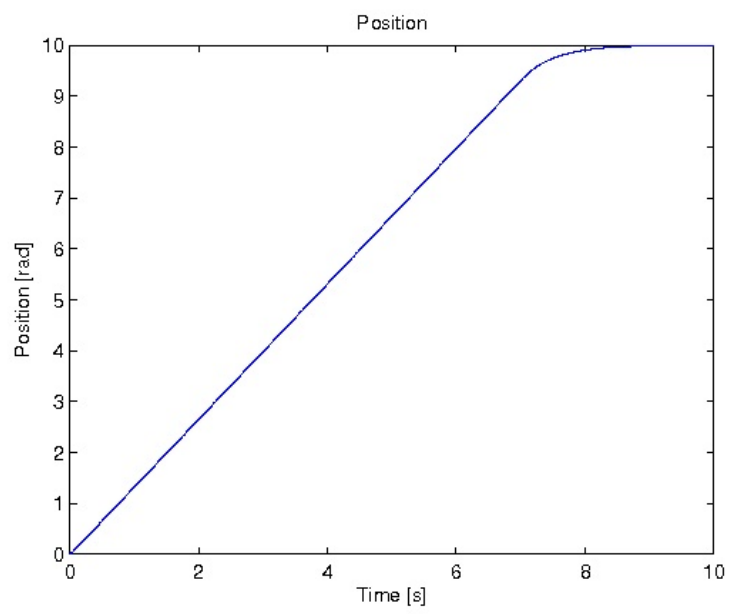

Fig. 10. Position result of sliding mode control.

\section{InTERnEt BASEd MEASUREMEnts}

Measurement is one of the key steps for the students to understand the theory. The experiments are designed in such way that they can be accessed through internet connection, so physical presence is not required. This makes it possible for universities to share their hardware.

In Fig. 12 the architecture of the remote laboratory system can be seen. The DC servo motor is turned on and off (with a Power Supply Unit, controlled by a D/A card), every time a student $\log s$ in to the system. This is required, because of security rules, which declare that experimental laboratory equipment cannot be turned on $24 \mathrm{~h}$ a day. As the system operates on standard Windows environment, which does not

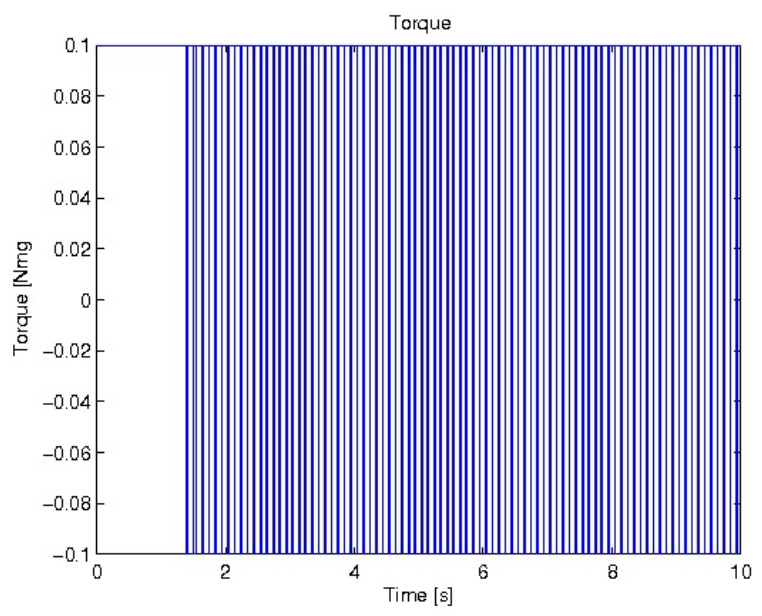

Fig. 11. Torque result of sliding mode control.

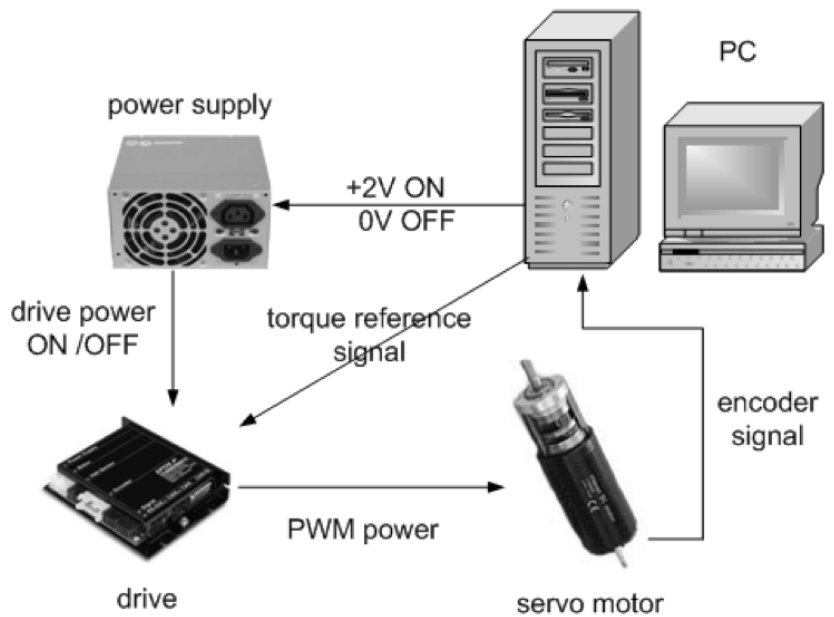

Fig. 12. System architecture.

guarantee real-time in any interrupt or timer event occasion, an extension is needed. A software solution is used (provided by IntervalZero): it is possible to create timers with 100 microseconds interval, with a maximum of 0.001 nanosecond yield. Not only the running environment is created, it seamlessly integrates itself to $\mathrm{C}++$ compilers, which allows running programs without modification in real time environment. With this solution more user friendly programming of real time applications can be achieved. The usability of the real time extension has been proven in industrial applications.

In order to control the DC motor connected to PC, the following system components performing basic functions are needed:

1) A card generating analogue output signals to turn on/off the drive and generate the reference signal (e.g. D/A card)

2) A card measuring input encoder signals forwarding it to the PC (e.g. A/D card or counter card)

3) A real-time clock that can schedule signal sampling or task execution

The DC servo motor (Maxon A-max 110961) has the following main characteristics:

$$
\begin{aligned}
& P=11 \mathrm{~W} ; V=15 \mathrm{~V}, R_{a}=3.58 ; L_{a}=0.33 \mathrm{mH} ; k_{m} \\
& =17.6 \mathrm{mNm} / \mathrm{A} ; k_{s}=5411 / \mathrm{Vmin} .
\end{aligned}
$$

To keep up with web trends and technology innovations, the remote laboratory is now web based. This reduces network traffic overload, which was caused by Remote Desktop Connection protocol. Only the controller instructions are transmitted from the client browser to the server. This is done through a form in the web page. The user writes its own controller to the textfield, with pushing the send in measurement button the experiment is run. The system can be seen in Fig.13.

There are four pre-defined state variables, which are always stored, but students can define up to six more of their own state variables such as the error etc. The four pre-defined state variables are the following:

- ResultData.Time - current time instance

- ResultData.Position - current position of the motor

- ResultData.Velocity - current speed of the motor

- ResultData.Torque - the current input torque of the motor 


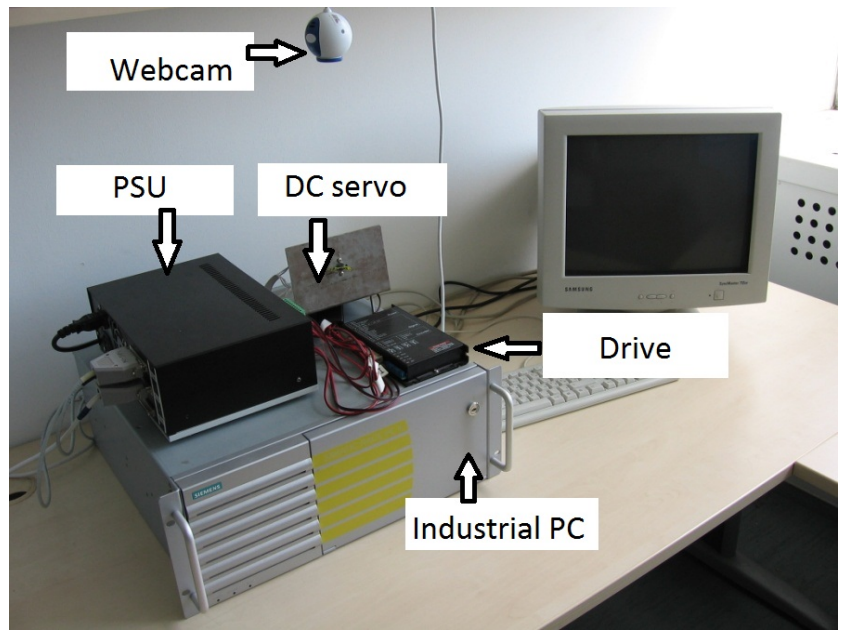

Fig. 13. Real implementation of the system.

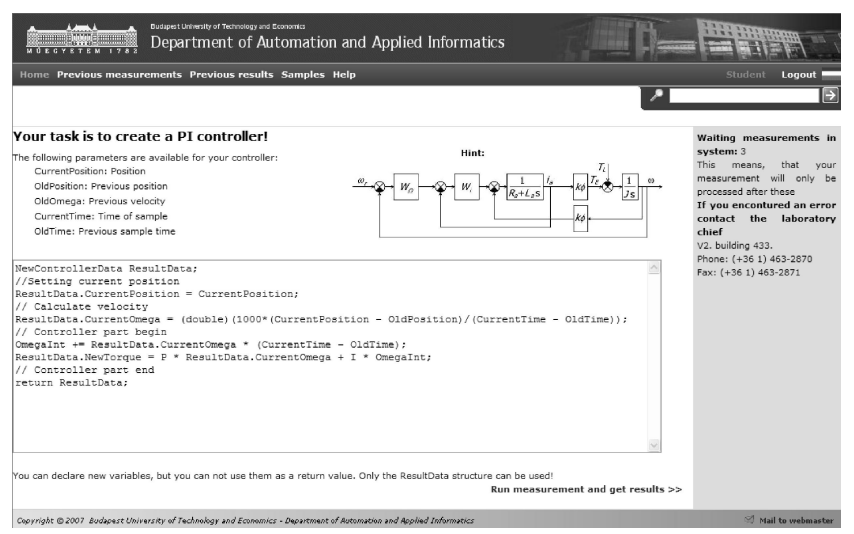

Fig. 14. Website of the remote laboratory.

After the experiment is finished the measurement results are available for download on the website for further evaluation.

\section{A. An example sliding mode control measurement}

In this exercise Closed Loop measurements will be performed with the DC motor. The task is to design a sliding mode controller for the position of the motor. The constant reference position is set to $\alpha_{\text {ref }}=10 \mathrm{rad}$.

The position and speed error are defined as

$$
\alpha_{\text {error }}=\alpha_{\text {ref }}-\alpha_{\text {motor }}, \Omega_{\text {error }}=0-\Omega_{\text {motor }}
$$

The sliding surface is selected as

$$
\sigma=\lambda \alpha_{\text {error }}+\Omega_{\text {error }}
$$

The control law is selected as

$$
\text { torque }=0.1 \text { sign } \sigma
$$

The code, which is written by the student, is divided to two sections: variable declaration and controller implementation. Only the filtered solution is presented here:

Variable declaration:

float sigma, error, error dot;

float ref $=10.0$;

float lambda $=0.5$;

static float $z \quad 1=0.0, z \quad 2=0.0, z \quad 3=0.0$;

static float ztmp $1=0.0$, ztmp $2=0.0$;

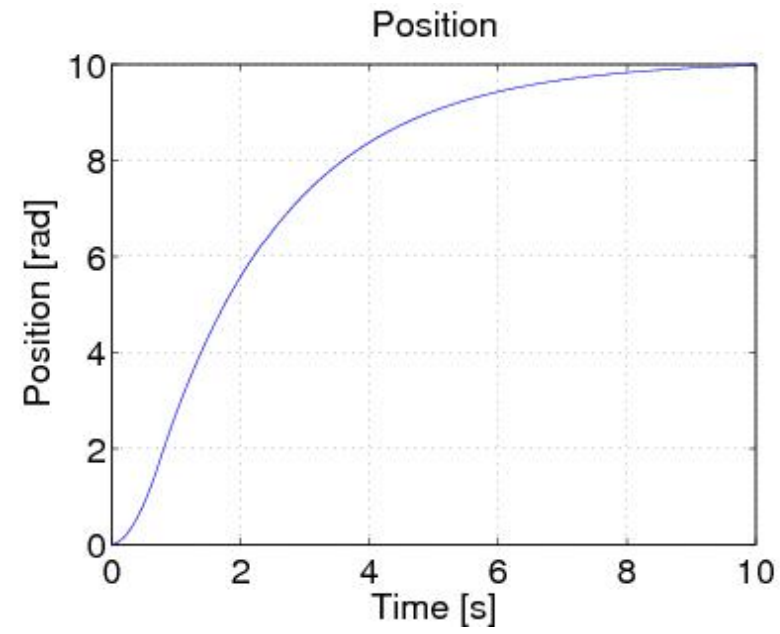

Fig. 15. Experiment result (position).

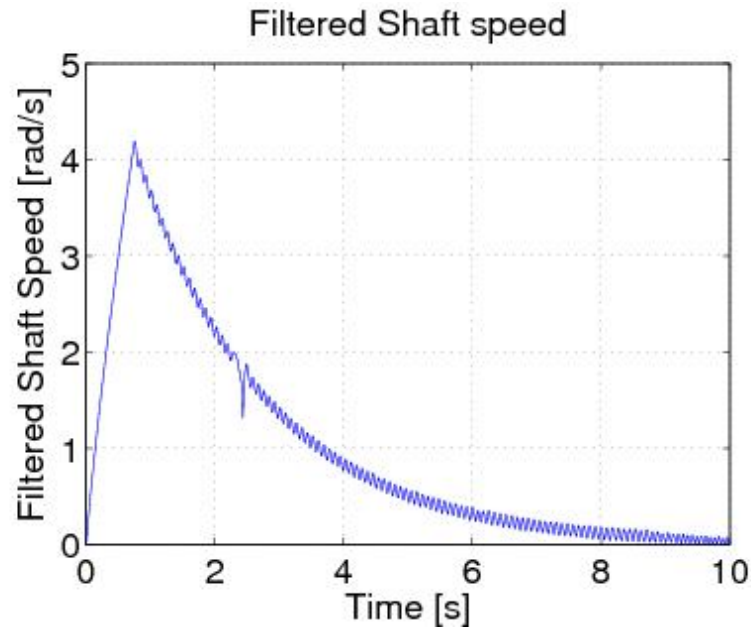

Fig. 16. Experiment result (filtered velocity).

float $\mathrm{zd11}=1, \mathrm{zd12}=0.0010, \mathrm{zd13}=0.0000$;

float $z d 21=-0.0005, z d 22=0.9999, z d 23=0.0010$; float $z d 31=-0.9851, z d 32=-0.2960, z d 33=0.9703$; float bzd1 $=0.0000, \mathrm{bzd} 2=0.0005, \mathrm{bzd} 3=0.9851$;

Controller implementation:

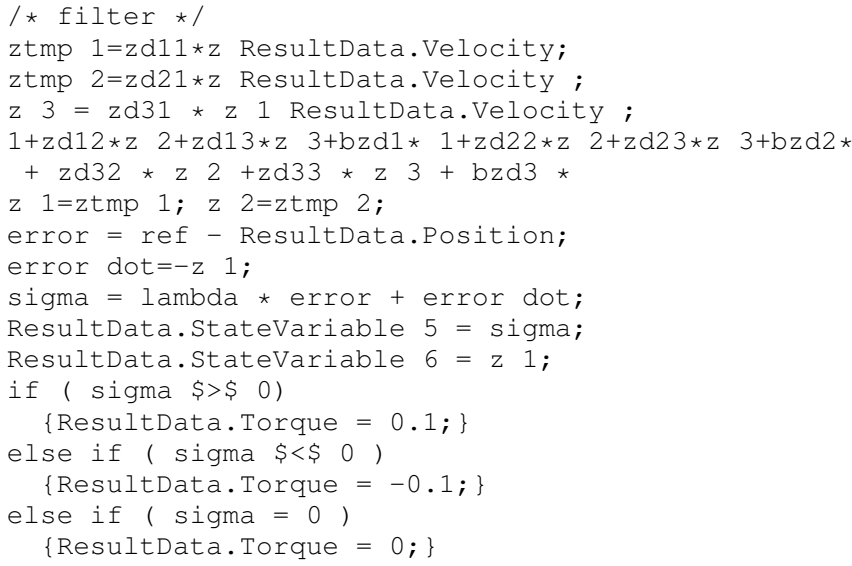

The results can be seen in Fig. 15-18. 


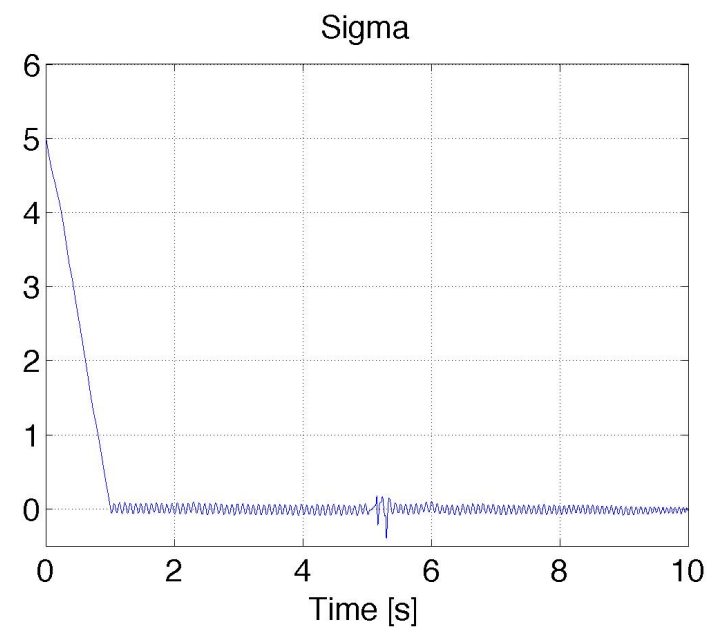

Fig. 17. Experiment result (sigma).

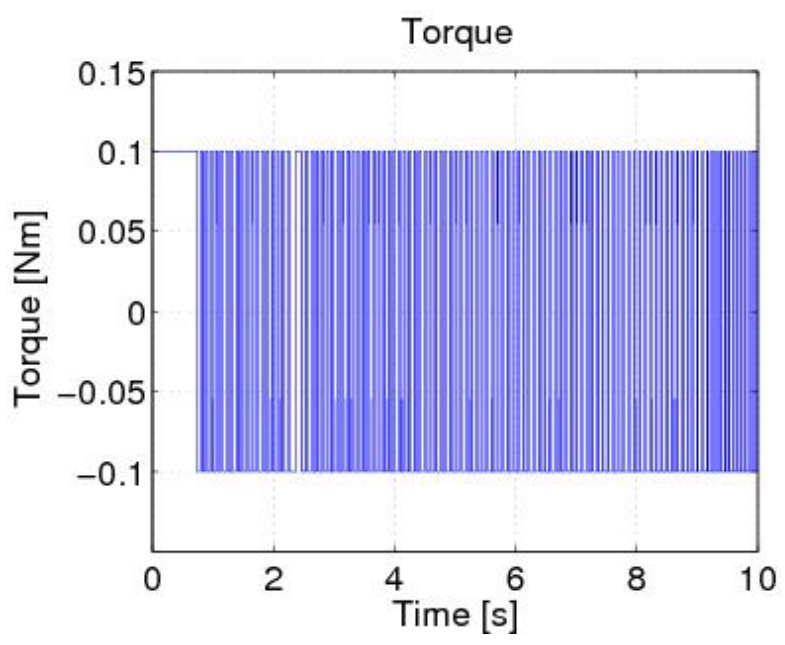

Fig. 18. Experiment result (input torque).

\section{CONCLUSIONS}

A complete distance learning program is presented starting from the animation and ending at internet based measurement including theoretical background with a special emphasis on sliding mode control. The development of such educational program needs a complete new way of thinking, some elements of this new educational approach were presented in this paper. Students can carry out sliding mode control experiments on a remote DC servo motor based on the paper.

\section{ACKNOWLEDGMENT}

The research was supported by HUNOROB project (HU0045), a grant from Iceland, Liechtenstein and Norway through the EEA Financial Mechanism and the Hungarian National Development Agency and the National Science Research Fund (OTKA K62836) and Control Research Group of Hungarian Academy of Science and the National Research and Technology Agency, (ERC_09) (OMFB-01677/2009).

\section{REFERENCES}

[1] P. Bartal, J. Hamar, R. K. Jardan, P. Korondi, I. Nagy, Z. Sepa, Z. Suto, K. Zaban, H. Funato, E. Masada, and S. Ogasawara, "Learning multimedia software for teaching nonlinear dynamics," in Proc. Control in Power Electronics and Motion Control (IPEC'05), Apr. 2005.
[2] V. Fedak, P. Bauer, V. Hajek, H. Weiss, B. Davat, S. Manias, I. Nagy, P. Korondi, R. Miksiewicz, P. Duijsen, and P. Smektal, "Interactive elearning in electrical engineering," in Proc. EDPE'03, pp. 368-373, Sep. 2003.

[3] Bauer P, Dudak J, Maga D, et al., "Distance practical education for Power Electronics," INTERNATIONAL JOURNAL OF ENGINEERING EDUCATION, Vol. 23, Issue 6, pp. 1210-1218, 2007.

[4] Bauer P, Fedak V, Hajek V, et al., "Survey of distance laboratories in power electronics," 39th IEEE Power Electronic Specialists Conference (PESC 08), Jun. 2008.

[5] G. Sziebig, B. Takarics, P. Korondi: "Control of an Embedded System via Internet," IEEE Trans. Ind. Electron., Vol. 57, No. 10, pp. 3324-3333, Oct. 2010.

[6] K. Saito, K. Kamiyama, T. Ohmae, and T. Matsuda, "A microprocessorcontrolled speed regulator with instantaneous speed estimation for motor drives," IEEE Trans. Ind. Electron., Vol. 35, No. 1, pp. 95-99, Feb. 1988.

[7] C. Chan, S. Hua, and Z. Hong-Yue, "Application of fully decoupled parity equation in fault detection and identification of dc motors," IEEE Trans. Ind. Electron., Vol. 53, No. 4, pp. 1277-1284, Jun. 2006.

[8] F. Betin, A. Sivert, A. Yazidi, and G.-A. Capolino, "Determination of scaling factors for fuzzy logic control using the sliding-mode approach: Application to control of a dc machine drive," IEEE Trans. Ind. Electron., Vol. 54, No. 1, pp. 296-309, Feb. 2007.

[9] Kumar P, Bauer P, "Improved analytical model of a permanent-magnet brushless DC motor," IEEE TRANSACTIONS ON MAGNETICS, Vol. 44, Issue 10, pp. 2299-2309, Oct. 2008.

[10] M. Boussak and K. Jarray, "A high-performance sensorless indirect stator flux orientation control of induction motor drive," IEEE Trans. Ind. Electron., Vol. 53, No. 1, pp. 41-49, Feb. 2006.

[11] J. Moreno, M. Ortuzar, and J. Dixon, "Energy-management system for a hybrid electric vehicle, using ultracapacitors and neural networks," IEEE Trans. Ind. Electron., Vol. 53, No. 2, pp. 614-623, Apr. 2006.

[12] G. Sziebig, I. Nagy, R K Járdán, P. Korondi, "Integrated multimedia educational program of a DC servo system for distant learning," 13th Power Electronics and Motion Control Conference (EPE-PEMC 2008), 2008.

[13] V. Utkin and K. Young, "Methods for constructing discontinuous planes in multidimensional variable structure systems,"' Vol. 31, No. 10, pp. 1466-1470, Oct. 1978

[14] K. Abidi and A. Sabanovic, "Sliding-mode control for high-precision motion of a piezostage," IEEE Trans. Ind. Electron., Vol. 54, No. 1, pp. 629-637, Feb. 2007.

[15] F.-J. Lin and P.-H. Shen, "Robust fuzzy neural network sliding-mode control for two-axis motion control system," IEEE Trans. Ind. Electron. Vol. 53, No. 4, pp. 1209-1225, Jun. 2006.

[16] C.-L. Hwang, L.-J. Chang, and Y.-S. Yu, "Network-based fuzzy decentralized sliding-mode control for car-like mobile robots," IEEE Trans. Ind. Electron., Vol. 54, No. 1, pp. 574-585, Feb. 2007.

[17] A. G. Filippov, "Application of the theory of differential equations with discontinuous right-hand sides to non-linear problems in automatic control," in 1st IFAC congress, pp. 923-925, 1960.

[18] — "Differential equations with discontinuous right-hand side," Ann Math Soc. Transl., Vol. 42, pp. 199-231, 1964.

[19] A. G. Lukuyanov and V. I. Utkin, "Method of reducing equations of dynamic systems to regular form," Transactions on Automation and Remote Control, Vol. 42, No. 1, pp. 413-420, 1981.

[20] P.Korondi,J.-X.Xu,andH.Hashimoto,"Sectorslidingmodecontroller for motion control," in 8th Conference on Power Electronics and Motion Control, Vol. 5, pp. 254-259, 1998.

[21] Bauer P, van Duijsen PJ, "Challenges and advances in simulation," 36th Annual IEEE Power Electronic Specialists Conference (PESC 05), Jun. 2005.

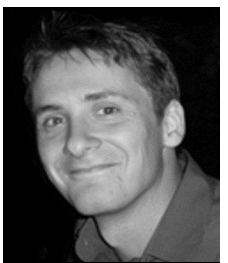

Bela Takarics (S'08) received the M.S degree from the Budapest University of Technology and Economics, Budapest, Hungary, in 2007, in Mechanical Engineering. He is currently a Ph.D. student at the Budapes University of Technology and Economics, Budapest, Hungary. His research interests include Tensor Product transformation based control, sliding mode control, elearning, robotics. 


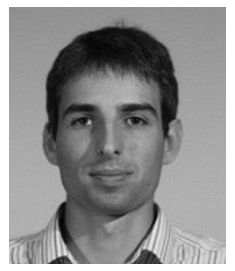

Gabor Sziebig (S'07) received the M.S degree from the Budapest University of Technology and Economics, Budapest, Hungary, in 2007, in Technical Informatics. $\mathrm{He}$ is currently a Ph.D. student at Narvik University College, Narvik, Norway. His research interests include robotics, manufacturing, teleoperation, vision systems, cognitive communication channels.

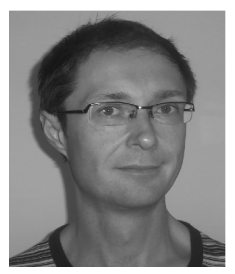

Bjørn Solvang received the B.Sc degree from Narvik University College in 1990 and the M.Sc degree from the Norwegian University of Science and Technology in 1992, all in mechanical engineering. He received his Dr. ing. degree from the Norwegian University of Science and Technology in 2003 in production engineering. Since 1995, he has been with Narvik University College in Norway where he currently works at the Industrial Engineering department. His research interest are robotics, computer integrated manufacturing and virtual manufacturing. Dr. Solvang is a founding member of the Norwegian- Hungarian research laboratory "Emerging Information Technology in Manufacturing (ITM)" and he is a member of the subcommittee "Computational Intelligence" within the IEEE IES Computer and control systems.

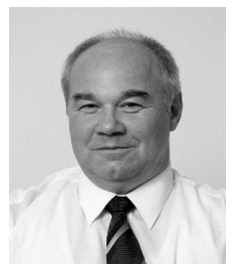

Péter Korondi (M'98) received the Dipl. Eng. and $\mathrm{Ph} . \mathrm{D}$. degrees in electrical engineering from the Technical University of Budapest, Budapest, Hun- gary, in 1984 and 1995, respectively. Since 1986, he has been with Budapest University of Technology and Economics (formerly the Technical University of Budapest). From April 1993 to April 1995, he worked in the laboratory of Prof. Harashima and Prof. Hashimoto at the Institute of Industrial Science, The University of Tokyo, where he continues to spend a month each year, working on joint research. As a result of this cooperation, the Intelligent Integrated System JapaneseHungarian Joint Laboratory was founded in 2001. His research interests include telemanipulation and motion control. Dr. Korondi is a founding member of the International PEMC Council, which became a chapter of the European Power Electronics Association. 